\title{
Fungal records database of Khanty-Mansi Autonomous Okrug - Yugra
}

\author{
Nina Filippova ${ }^{1, *}$, and Tatiana Bulyonkova ${ }^{2}$ \\ ${ }^{1}$ Yugra State University, Environmental Dynamics and Global Climate Change-UNESCO chair, \\ 628012, Chekhova street, 16, Khanty-Mansiysk, Russia \\ ${ }^{2}$ A.P. Ershov Institute of Informatics Systems Russian Academy of Sciences, 630090, prospect \\ Lavrentyeva, 6, Novosibirsk, Russia
}

\begin{abstract}
The mycological research in the Northern part of Western Siberia becomes quite developed by now to be reviewed, in Khanty-Mansi Autonomous Okrug - Yugra reaching about 150 scientific works accomplished mainly from the second half of XXI century. There is even greater need in accumulating fungal records reported from different publications in a standardized regional database. This database should be organized according to contemporary demands of biodiversity informatics, to be compatible and accessible by other researchers. Organized in 2016, the Fungal Records Database of Yugra, presently contains about 14000 records of 2500 species of fungi and fungi-like organisms recorded in the area. This paper describes the database organization and accumulated fungal records and introduces the research conducted in the field of mycology in Yugra from the beginning of the XX century up to present.
\end{abstract}

\section{Introduction}

The mycological research in Khanty-Mansi Autonomous Okrug - Yugra stems from isolated studies in the beginning of the XX century, yet regular and systematic research only began in the 70-80s. Over the following decades several dozens of researchers worked in the area, and a total of about 150 scientific works were published [1, 2]. However, these were scattered works which have not been summarized until now and there has not been a general checklist for the area. The recent development of biodiversity informatics opened a new way of accumulation species records in large standardized databases which can be considered as a substitute to printed checklists of older times. With this in mind, we decided to review the available publications, extract fungal records, and analyse the accumulated knowledge of fungal biodiversity in Yugra region according to the modern requirements to the biodiversity databases.

The goal of this paper is to describe the structure and the field format of the regional database of fungal records, make the analysis of accumulated presently data on fungal diversity in Yugra, and make an overview of the mycological research reflected in the database.

\footnotetext{
* Corresponding author: filippova.courlee.nina@gmail.com
} 


\section{Organization of a regional Fungal Records Database}

The Fungal Records Database of Yugra (FReDY) is aimed at summarizing the species records accumulated in the course of previous mycological studies in Yugra. The database structure is based on Darwin Core format and includes about 30 fields describing taxa, record locations and other auxiliary information (table 1). Google Sheets, a Web-based service, was used as the basis for a simple database. The elements of the relational structure were created using reference tables and queries [3]. Such database can be filled simultaneously by many specialists, and a common data format will be provided.

Table 1. The structure of the database is represented by the following tables and fields.

\begin{tabular}{|c|c|}
\hline Tables & Fields \\
\hline Main Data & $\begin{array}{l}\text { recordNumber-individual record number (increment numbers, } \\
\text { formatted «FReDY-xxxxx»); originalNameUsage - the names of the } \\
\text { species as reported in the source; scientificName - name of species, in } \\
\text { accordance with modern taxonomy and nomenclature data (filled } \\
\text { automatically with a query from the Species table); } \\
\text { identificationQualifier - the quality of the identification (for notes like } \\
\text { cf., aff.); taxonRemarks - notes about the discrepancy in spelling of the } \\
\text { species names; taxonRank - the taxonomic rank of the entry given in the } \\
\text { scientificName field; genus - genus (filled automatically with a query } \\
\text { from the scientificName field); group - the traditional group (filled } \\
\text { automatically with a query from the Taxonomy table, the term is absent } \\
\text { in DwC); family - family (filled automatically with a query from the } \\
\text { Taxonomy table); order - order (filled automatically with a query from } \\
\text { the Taxonomy table); bibliographicCitation - reference to the literature } \\
\text { source reporting the registration of the species; stateProvince - the } \\
\text { highest administrative subdivision of Russia (language - English, source } \\
\text { - Getty Thesaurus of Geographic Names, } \\
\text { http://www.getty.edu/research/tools/vocabularies/tgn); county - rayon } \\
\text { (language - English, source of names - Yandex.Maps); locality - } \\
\text { location of the find (language - English, source of names - } \\
\text { Yandex.Maps); verbatimLocality - the location of the find in the original } \\
\text { (Russian) language as reported in the source; protectedArea - the } \\
\text { territory of protected areas (term is absent in DwC); habitat - habitat } \\
\text { (description of vegetation type, landscape and / or micro-conditions, } \\
\text { language - English); verbatimHabitat - habitat in the original (Russian) } \\
\text { language (term is absent in DwC); catalogNumber - herbarium number } \\
\text { of the record, if reported in publication; } \text { eventDate - the date of } \\
\text { registration of the find, if reported in publication; decimalLatitude - } \\
\text { latitude (Decimal degrees); decimalLongitude - longitude (Decimal } \\
\text { degrees); geodeticDatum - datum (most often WGS } 84 \text { ); } \\
\text { coordinateUncertaintyInMeters - the approximation of the coordinate } \\
\text { (see DwC definition) }\end{array}$ \\
\hline Synonymy & $\begin{array}{l}\text { A list of species names and corresponding current synonyms (filled in } \\
\text { manually by the community of specialists [3]) }\end{array}$ \\
\hline References & Bibliographic records (about 20 standard bibliographic fields) \\
\hline
\end{tabular}




\begin{tabular}{|c|c|}
\hline Geography & $\begin{array}{r}\text { Geographic tree from Rayon to Country (built on the basis of Getty } \\
\text { Thesaurus of Geographic Names and Yandex.Maps) }\end{array}$ \\
\hline Taxonomy & $\begin{array}{r}\text { Taxonomic tree including group, order, family and genus (compiled } \\
\text { manually based on a number of taxonomic sources) }\end{array}$ \\
\hline Account & $\begin{array}{c}\text { Used to obtain statistical information using queries, for example, unique } \\
\text { lists of species for individual territories and taxonomic analyses }\end{array}$ \\
\hline
\end{tabular}

\section{Analysis}

Presently, the database contains over 14000 fungal records in the region and adjacent areas, reported in 72 scientific publications. According to the database summary report, there are currently about 2500 species of fungi and fungi-like organisms recorded in Yugra. The richest groups are the agaricoid basidiomycetes (31\%), lichens (33\%) and aphyllophoroid basidiomycetes (19\%). The less studied groups are the ascomycetes (8\%), myxomycetes $(3 \%)$, heterobasidiomycetous fungi $(<1 \%)$, and yeasts $<1 \%)$.

Regarding the territorial coverage of the records, all administrative divisions are represented in the database, however, the majority (72\%) of collections were registered in three administrative divisions (Khanty-Mansiyskiy - 30\%, Berezovskiy - 24\% and Surgutskiy district - 18\%) (figure 1).

The FReDY database was uploaded to GBIF (YSU BC publisher) by 11 November 2017; it is available for review of metadata and provides open access to the data upon download [4].

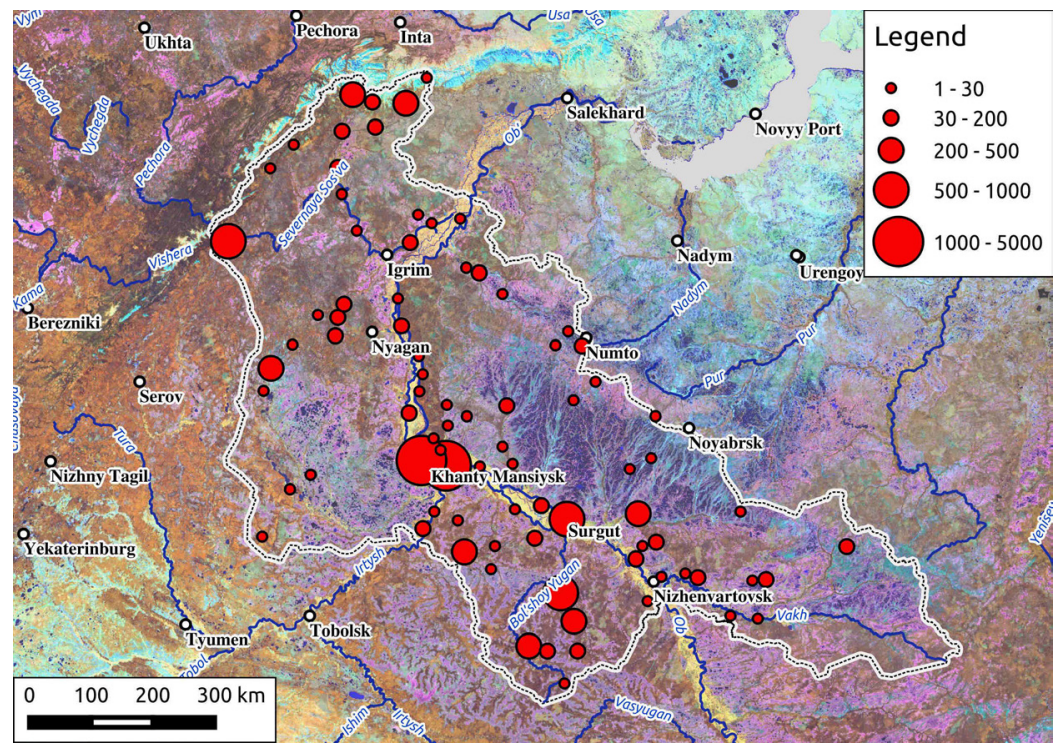

Fig. 1. The map of records in FReDY in 2017. The clustering of points was made within a radius of $20 \mathrm{~km}$; the scale breaks were selected manually after plotting the frequency distribution histogram.

\section{Overview of the mycological research reflected in the database}

\subsection{Lignicolous basidiomycetes}


Lignicolous basidiomycetes are a well-studied ecological group in the region and about $35 \%$ of records in FReDY represented by this group. Viktor A. Mukhin analysed the geography and ecology of lignicolous basidiomycetes throughout all zones of Western Siberia from the forest-steppe zone in the South to tundra-steppe in the North. He theorized on the geographic aspect of the possible origin of the local mycota, outlined species distribution ranges and analysed ecological factors affecting them (e.g. humidity, temperature, substrate specialization, or interspecific competition). Communities of lignicolous fungi were analysed based on forest types: dark coniferous, light coniferous, broad-leaved, small-leaved or floodplain forest communities. The stages of wood decomposition in Western Siberia are described and characterized by the sets of species of the corresponding fungal community. Finally, rare species, for the whole territory or its particular habitats and zones, were revealed, complete with conservation recommendations.

Stanislav P. Arefyev and Iraida V. Stavishenko continued the study of lignicolous basidiomycetes in the region. They have contributed greatly to the knowledge of species diversity in most of the region's conservation areas and performed ecological monitoring in the areas of oil and gas extraction. I. V. Stavishenko described in detail the lignicolous macrofungi of the middle-taiga $\mathrm{Ob}$ basin region in her $\mathrm{PhD}$ thesis. S. P. Arefyev applied mathematical methods of ecological modelling to predict species composition of lignicolous fungi depending on substrate characteristics, climate and disturbance level of the forest.

\subsection{Terricolous macrofungi}

Terricolous macrofungi are a key ecological group of saprotrophs and ectomycorrhizal species and about $30 \%$ of records in FReDY represented by this group. The diversity of macrofungi was studied in a number of districts of KhMAO: the most thoroughly studied area is centred around the regional capital, Khanty-Mansiysk, and in the south-east part, in and near the Yuganskiy nature reserve). Nina V. Filippova with co-authors has been studying the species diversity and fungal community structure in forests near KhantyMansiysk while Elena A. Zvyagina and Tatiana M. Bulyonkova continuously monitor the fungal biodiversity in the Yuganskiy nature reserve. Anton G. Shiryaev has published a study of clavarioid basidiomycetes in a conservation area. In addition to the annotated species lists, a number of works deal with specific aspects of ecology, biology and abundance of rare, protected and otherwise noteworthy species.

\subsection{Phytopathological studies}

A variety of studies of plant pathogens, including pathogens of forests, have been carried out in the region. Stanislav P. Arefyev studied fungal pathogens of the Siberian pine (Pinus sibirica) and described the ecological causes of the diseases along with recommendations on the afforestation of Siberian pine cultures. Tatiana A. Makarova with co-authors made studies on the causes and extent of mycopathological diseases of urban spaces around the city of Surgut and in some other parts of the region.

\subsection{Other groups of fungi and fungus-like organisms}

The lichens represent a large part of fungal diversity described for the region and $20 \%$ of records in FReDY. The lichen mycota was described in several conservation areas, with the highest diversity revealed in the North Ural mountains, reaching around 900 species within a relatively small area (Nelly V. Sedelnikova). 
The species diversity of myxomycetes was covered by two studies in conservation areas (Konstantin A. Fefelov).

The whole territory of the Khanty-Mansi Autonomous Okrug is strongly bogged, with peatlands covering up to $70 \%$ of the area. The fungal communities of peatlands have been studied in many aspects, including the diversity of macrofungi, microfungi on different litter debris of bog plants, yeasts on Sphagnum and bog plants, lignicolous fungi of bogdwelling trees (the Scots pine) (Nina F. Filippova). Totally fungal records collected during the research in peatlands represent about $8 \%$ of records accumulated in the database.

The authors are grateful to Ilya Filippov for preparation of a graph.

\section{References}

1. N.V. Filippova, S.P. Arefyev, T.M. Bulyonkova, E.A. Zvyagina, V.I. Kapitonov, T.A. Makarova, V.A. Mukhin, I.V. Stavishenko, E.I. Tavshanzhi, A.G. Shiryaev, Environmental dynamics and global climate change 8, 18-28 (2017)

2. N.V. Filippova, S.P. Arefyev, T.M. Bulyonkova, E.A. Zvyagina, V.I. Kapitonov, T.A. Makarova, V.A. Mukhin, I.V. Stavishenko, E.I. Tavshanzhi, A.G. Shiryaev, Environmental dynamics and global climate change 8, 29-45 (2017)

3. S.Yu. Bolshakov, N.V. Filippova, K.O. Potapov, D.V. Ageev, S.V. Volobuev, International Conference "The use of modern information technologies in botanical investigations» (Apatity, 2017)

4. N. Filippova, S. Arefyev, T. Bulyonkova, E. Zvyagina, V. Kapitonov, T. Makarova, V. Mukhin, I. Stavishenko, E. Tavshanzhi, A. Shiryaev, Fungal records database of Khanty-Mansi Autonomous Okrug - Yugra (Russia, West Siberia). Yugra State University Biological Collection (YSU BC). Occurrence Dataset https://doi.org/10.15468/hfje31 accessed via GBIF.org on 2017-11-19 (2017) 